\title{
For Debate: May the Use of the Polyene Macrolide Natamycin as a Food Additive Foster Emergence of Polyene-Resistance in Candida Species?
}

\author{
Axel Dalhoff ${ }^{*}$ \\ Faculty of Mathematics and Natural Sciences, Christian Albrechts Universitat zu Kiel, 24118 Kiel, Germany
}

"Corresponding author: Axel Dalhoff, Faculty of Mathematics and Natural Sciences, Christian Albrechts Universitat zu Kiel, 24118 Kiel, Germany, Tel: +49-202-2655236; Fax: +49-202-2655297;E-mail: adalhoff@t-online.de

Received date: July 01, 2017; Accepted date: July 18, 2017; Published date: July 20, 2017

Copyright: @2017 Dalhoff A. This is an open-access article distributed under the terms of the Creative Commons Attribution License, which permits unrestricted use, distribution, and reproduction in any medium, provided the original author and source are credited.

\begin{abstract}
Natamycin is approved almost worldwide as a food additive for surface treatment of cheese and sausages. Its use is considered to be safe as Natamycin is extremely sensitive to ultraviolet light and an acidic $\mathrm{pH}$, so that products exposed to light in the retail industry and food stores are likely free from Natamycin. However, the use of an acid-, heat- and light stable Natamycin formulation in yoghurt has recently been authorized in the USA as well as in Australia and New Zealand. Furthermore, yoghurt is stored in sealed cups in refrigerated shelves, so it will not be exposed to light and thus not be inactivated during storage. Consequently, the resident flora will be exposed to Natamycin and it may exert a resistance selective pressure on faecal Candida spp. hypothetically selecting strains being resistant to Amphothericin B. In this review literature has been evaluated addressing the questions if Natamycin may foster emergence of polyene-resistance. This concern is supported by the facts that first, polyeneresistance could be elicited in vitro and in vivo. Second, as Azoles being used in agriculture and hospitals as well as polyenes share some common resistance mechanisms a polyene-resistance reservoir does exist in environmental and clinical fungal isolates. Third, Natamycin may amplify Amphothericin B resistance as fourth, resistance can in principal be spread amongst fungi by horizontal gene transfer. To preserve clinical efficacy of Amphothericin B for treatment of serious, life threatening infections, the use of Natamycin as a food-preservative should be limited to an absolute minimum
\end{abstract}

Keywords: Polyene resistance; Food additive; Exposition of faecal flora; Selective pressure; Preservation of Amphothericin B

\section{Introduction}

Preservation of food is of concern ever since mankind began to socialize and to migrate. Both, a growing population and thus a growing crisis of food supply, and the evolution of an industrial society living in large metropolitan areas demands that wheat yields continue to increase and fungal spoilage as well as losses of food to be reduced to a minimum. Thus, plant protectives and food additives for preservation of foodstuffs have been developed and accepted by the regulatory authorities. Diverse technologies of plant protection and food preservation have been developed such as use of chemical preservatives or use of antimicrobial agents [1]. Antifungal Azoles are used in agriculture and the lantibiotic Nisin being active against Grampositive bacteria and the polyene macrolide (in the following "polyene") Natamycin being active against filamentous fungi but inactive against bacteria are used as food preservatives. However, resistance development is a serious risk associated with the use of antimicrobials as food additives and environmental fungicide use, respectively [2-6]. Although the overall level of resistance to antifungal agents is still low, studies have revealed that azole-resistance and surprisingly-Amphothericin B-resistance, too, could indeed be detected in environmental strains of Aspergillus fumigatus [6-11] as well as in environmental Candida spp. Strains [12-15]. These studies indicate that the extensive agricultural use of antifungals triggers resistance development in environmental fungi beyond the limits of structural classes of antimycotics thus probably creating a threat to human health.
The polyene Natamycin, too, is used in agriculture and may be used in horticulture. It is approved in the USA as a fungistat to prevent fungal contamination of growth media in enclosed mushroom production facilities and for indoor post-harvest treatment of several fruits Table $1[16,17]$.

\begin{tabular}{|c|c|c|}
\hline Country & $\begin{array}{l}\text { Matrix in/on which } \\
\text { Natamycin is permitted }\end{array}$ & $\begin{array}{l}\text { Maximum permitted } \\
\text { level }(\mathrm{mg} / \mathrm{L}, \mathrm{mg} / \mathrm{kg}, \mathrm{mg} / \\
\text { surface area) }\end{array}$ \\
\hline EU & $\begin{array}{l}\text { Surface of cheese } \\
+ \text { sausages }\end{array}$ & $1 \mathrm{mg} / \mathrm{dm}^{2}$ \\
\hline \multirow{7}{*}{ SA } & Surface of cheese & $10 \mathrm{mg} / \mathrm{kg}$ \\
\hline & Plastic coating of cheese & $500 \mathrm{mg} / \mathrm{kg}$ \\
\hline & $\begin{array}{l}\text { Sausages, manufactured } \\
\text { fish products, canned food }\end{array}$ & $6 \mathrm{mg} / \mathrm{kg}$ \\
\hline & Manufactured meat products & $\begin{array}{l}500 \mathrm{mg} / \mathrm{kg} \text { on casing or } \\
6 \mathrm{mg} / \mathrm{kg} \text { in contents }\end{array}$ \\
\hline & Fresh fruit, fruit juices & $5 \mathrm{mg} / \mathrm{kg}$ \\
\hline & yoghurt & $10 \mathrm{mg} / \mathrm{kg}$ \\
\hline & Wine, alcoholic beverages & $30 \mathrm{mg} / \mathrm{L}$ \\
\hline \multirow{3}{*}{ USA } & $\begin{array}{l}\begin{array}{l}\text { Surface of cheese } \\
\text { +sausages }\end{array}\end{array}$ & $20 \mathrm{mg} / \mathrm{kg}$ \\
\hline & Soft tortillas, salad dressing & $20 \mathrm{mg} / \mathrm{kg}$ \\
\hline & yoghurt & $5-10 \mathrm{mg} / \mathrm{kg}$ \\
\hline
\end{tabular}




\begin{tabular}{|l|l|l|}
\hline \multirow{4}{*}{} & Liquid egg products & $15 \mathrm{mg} / \mathrm{kg}$ \\
\cline { 2 - 3 } & $\begin{array}{l}\text { Citrus, avocado, kiwi, stone- } \\
\text { fruit, mango, pomegranate, } \\
\text { pome fruit }\end{array}$ & $6.6-13.3 \mathrm{oz} . / 100$ gallons \\
\cline { 2 - 3 } & pineapple & $0.18-1.44 \mathrm{oz} . / 100$ gallons \\
\cline { 2 - 3 } & cherries & $3.3-13-3 \mathrm{oz} . / 100$ gallons \\
\cline { 2 - 3 } & mushroom & $0.36-0.73$ oz/1000 feet2 \\
\hline \multirow{2}{*}{ Canada } & Surface of cheese & $20 \mathrm{mg} / \mathrm{kg}$ \\
\cline { 2 - 3 } & Grated/shredded cheese & $10 \mathrm{mg} / \mathrm{kg}$ \\
\hline \multirow{2}{*}{ Australia } & tortillas & $20 \mathrm{mg} / \mathrm{kg}$ \\
\cline { 2 - 3 } & bread & $14 \mathrm{mg} / \mathrm{kg}$ \\
\cline { 2 - 3 } & beverages & $5 \mathrm{mg} / \mathrm{l}$ \\
\hline \multirow{2}{*}{ New Zealand } & Surface of cheese & $15 \mathrm{mg} / \mathrm{kg}$ \\
\hline ARE & Surface of cheese & $12.5 \mathrm{mg} / \mathrm{kg}$ \\
\cline { 2 - 4 } & beer & $5 \mathrm{mg} / \mathrm{l}$ \\
\hline Kuwait & Permitted food additive & $2.5 \mathrm{mg} / \mathrm{kg}$ \\
\hline \multirow{2}{*}{ Russia } & Permitted food additive & \\
\hline & Surface of cheese & $5 \mathrm{mg} / \mathrm{kg}$ \\
\hline & Canned vegetables & \\
\hline
\end{tabular}

Table 1: Selected examples for food legislation on the use of natamycin (modified according to 16, 17; EU=European Union; SA=South Africa; USA=United States of America; ARE: United Arab Emirates).

It is also used in the USA as an additive to food or drinking water of broiler chickens for the reduction of poultry condemnations $[17,18]$. Furthermore, patents have been granted for the use of Natamycin in treatment of bananas and potatoes [19,20] or tulip bulbs [21]. Active packaging systems coated with Natamycin have been described for food preservation $[22,23]$. Natamycin is approved almost worldwide as a food additive for the preservation of cheese and sausages. The use of Natamycin in agriculture and horticulture may result in a dietary exposure to Natamycin. However, exposure is considered to be insignificant as Natamycin is applied indoors only and directly to commodities [17]. The use of Natamycin for surface treatment of cheese and sausages is also considered to be safe as Natamycin is extremely sensitive to ultraviolet light [24], so that products exposed to light in the retail industry and food stores are likely free from Natamycin. Natamycin formulations used in agriculture or horticulture, and for surface treatment of cheese and sausages are aqueous suspensions of Natamycin crystals [25,26].

Recently, the use of Natamycin in yoghurt has been authorized in the USA [27] as well as in Australia and New Zealand [28]. Moreover, yoghurt products containing 5-10 mg Natamycin/kg are commercially available in South Africa, Canada and China. In addition, Natamycin may be added to wine, alcoholic beverages or fruit juices Table 1. However, Natamycin is not only degraded by UV light but also at an acidic $\mathrm{pH}$ as it prevails in yoghurt, fruit juices and wine. Therefore, a chemically and microbiologically stable Natamycin formulation had to be developed $[29,30]$. The new formulation protects Natamycin from degradation by heat, light, and high or low $\mathrm{pH}$ and offers the advantage of a slow release $[29,30]$. In addition, yoghurt is stored in sealed cups in refrigerated shelves, so that Natamycin will not be exposed to light and thus not be inactivated during storage. Furthermore, the matrix yoghurt may shield Natamycin from degradation caused by an acidic $\mathrm{pH}$. This assumption is supported by findings that turkish yoghurt purchased in food stores contained 0.1 to $4.89 \mathrm{mg}$ Natamycin $/ \mathrm{kg}$ yoghurt although turkish dairy products should not contain any preservatives [31,32]. Natamycin recovery from yoghurt samples spiked with pure Natamycin was $89 \%$ to $99.5 \%$ $[32,33]$ and it was biologically active throughout the study period of 28 days [34] and 40 days [35]. Unfortunately, production and sampling dates were not specified in these publications, but data demonstrate that pure Natamycin retained its biological activity in stored turkish yoghurt products for more than four weeks. The characterization of the novel Natamycin formulation in the corresponding patents and the supportive evidence provided by the descriptive data from Turkey support the notion that the physicochemical properties as well as the biological and pharmacodynamic characteristics of the novel Natamycin slow release formulation to be used for the preservation of yoghurt, beverages, fruit juices, wine, etc. is not identical with those of the conventional formulation used for surface treatment of cheese and sausages. Furthermore, it should be considered that the use of a lightand acid stable Natamycin formulation as an additive to yoghurt, beverages, fruit juices, wine, etc. may expose the human resident fungal flora directly to the selective pressure of an anti-infective agent, while the use of a light- and acid unstable Natamycin formulation in agriculture or horticulture and as a food preservative may expose the environmental flora, if at all.

The theory that the consumption of Natamycin containing yoghurt may expose the resident faecal flora to Natamycin thus fostering emergence of resistance to polyenes in Candida spp. and jeopardizing the clinical efficacy of Amphothericin B [36] has been discussed controversially $[37,38]$. Evidence has been presented that Natamycin exerts a negligible in vitro resistance-selective potential in pathogenic yeasts and other probably opportunistic fungal pathogens [39]. Overall, development of Amphothericin B resistance seems to be slow under in vitro conditions and has seemingly not yet been a factor causing clinical problems; furthermore, reports on the recovery of resistant isolates from patients during Amphothericin B therapy are scarce [40], although a number of studies have described in vitro induction and in vivo selection of Amphothericin B resistance.

Reasons for concern were that the consumption of Natamycin containing yoghurt, beverages, fruit juices, wine, etc. may expose the human faecal Candida spp. flora to antimicrobially active drug concentrations [36]. Consumption of yoghurt containing the novel Natamycin formulation may result in an estimated 2-day daily intake of Natamycin from background and proposed uses for the total US population of 0.61 to $1.22 \mathrm{mg} /$ day [41]. Assuming that the entire amount of Natamycin consumed with yoghurt is deposited in the faeces and is freely available and thus antifungally active, mean faecal Natamycin concentrations exceed its MICs for Candida spp. [36]. Exposition of the gastrointestinal flora to Natamycin will be greater following wine drinking as in South Africa the maximal permitted Natamycin concentration in wine and alcoholic beverages amounts to $30 \mathrm{mg} / \mathrm{L}$ [16]. Consequently, Natamycin may exert a resistance selective pressure on faecal Candida spp. under these particular circumstances. Furthermore, fungi harbouring polyene resistance originating from environmental sources or having been selected as a consequence of Amphothericin B- or Nystatin therapy may render other faecal fungal species polyene resistant by horizontal gene transfer 
[36]. This hypothesis implies that first, polyene resistance can indeed be elicited in vitro and in vivo; second, that a polyene resistance reservoir does exist; third, that in case a polyene resistance reservoir does exist, Natamycin may exert a resistance selective potential thus amplifying Amphothericin B resistance, and fourth, that resistance can be spread. In the following literature is reviewed addressing these hypotheses.

\section{In vitro Development of Polyene-Resistance}

Continuously increasing minimal inhibitory concentrations (MICs) of Nystatin and Amphothericin B, respectively, developed in 33.6\% and $63.4 \%$ of the strains studied following at least 10 , and up to 100 transfers of the strains on polyene containing medium. MICs of Amphothericin B for Candida spp. increased approximately 500 to 1000 fold after 100 transfers [42]. MICs of C. albicans, C. stellatoides, C. parakrusei, C. guilliermondii, C. krusei, and C. tropicalis increased after 50 subcultures in Amphothericin B containing medium 1.2, 4.5, 25.0, 57.0, 60.0, 200.0 fold, respectively [43]. Exposure of $C$. albicans to the polyene candidin revealed that its MICs increased 14 and 150 fold after 14 and 25 transfers, while the Amphothericin B MICs increased 10-fold [44]. The same group described that $C$. albicans could be rendered 150-fold candidin and/or 4 to 60 fold Amphothericin B resistant but not Nystatin-resistant after 20 to 30 transfers in either of these polyenes [45]. Exposure of 12 strains of $C$. albicans to Amphothericin B for a total of 52 transfers revealed that MICs of Amphothericin B for all of the strains increased, but in only three strains resistance developed [46]. Likewise, development of Amphothericin B resistance was recorded from the $10^{\text {th }}$ transfer onwards for a total of 58 transfers; after about 10 transfers MICs were increased about three to fivefold only; induction of resistance proceeded rapidly once this moderate increase in MICs has been reached [47]. Increased Natamycin-MICs could be generated in $S$. cerevisiae and $S$. bailii. Natamycin MICs increased slowly up to the $20^{\text {th }}$ transfer, with a steep increase thereafter [48]. Others failed to generate polyene-resistant strains of Candida spp. Short term exposure to Nystatin resulted in a five-fold increase in MICs for one strain only, whereas the remaining four were unaffected [49]. Streekstra et al. [39] described that MICs of Natamycin increased minimally in 13 out of 20 tested strains and 4 strains showed a $>2$-fold increase in MICs following 12 to 36 transfers in Natamycin containing medium; one of these strains also showed significantly increased MICs of Amphothericin B and Nystatin. Furthermore, MICs of Natamycin remained unchanged in fungi isolated from cheese warehouses following 25 transfers [50] and no change in the composition or the sensitivity of the contaminating fungal flora isolated from cheese- or sausage factories has been observed [50-52].

Obviously, discrepant data were obtained either following long-term exposure with more than 30 transfers or short-term exposure with about 25 transfers or less. Thus, the use of small, rather than large increments of polyene concentrations and a large number of transfers over a long period of time are necessary to raise polyene-resistance in vitro, since significant increases in MICs (and thus induced polyeneresistance) had not occurred until 20-30 transfers had been made [43-49]. Consequently, long term exposure to sub-inhibitory Natamycin concentrations may in theory represent a potential hazard.

Apart from phenotypic changes, i.e. increasing MICs, any exposure of microorganisms to antimicrobials exerts a stress which is sensed by fungi and to which the microorganism responds in order to survive in a hostile environment. Such sensing and cellular signalling mechanisms contribute as much to antifungal drug-resistance as alterations in the drug target $[53,54]$. Candida albicans, Saccharomyces cerevisiae, Aspergillus fumigatus and Trichophyton rubrum develop compensatory responses related to changes in the cell membrane caused by exposure to sub-inhibitory concentrations of Amphothericin B, Nystatin, Azoles and other drug classes [55-67]. Changes in gene expression triggered by exposure to sub-inhibitory drug concentrations affects genes involved in eg. drug-target, i.e. ergosterol biosynthesis including genes identified as contributing to resistance, but also genes involved in transport, osmotic tolerance, oxidative stress and other genes more. This pleiotropic drug-resistance network contributes to the acquisition of resistance to antifungals beyond structural limits and spanning the fungal kingdoms $[53,54]$.

\section{Longitudinal Surveillance Studies Indicating the Existence of a Polyene Resistance Reservoir}

Harmonized CLSI and EUCAST methods of susceptibility testing [68-75] defined the Amphothericin B susceptible- and resistant breakpoints according to EUCAST definition as $<1 \mathrm{mg} / \mathrm{l}$ and $>1 \mathrm{mg} / \mathrm{l}$, respectively for C. albicans, C. glabrata, C. parapsilosis, C. tropicalis, and $C$. krusei [76] whereas the susceptible- and resistant breakpoints for $A$. fumigatus and $A$. niger are $<1 \mathrm{mg} / \mathrm{l}$ and $>2 \mathrm{mg} / \mathrm{L}$, respectively for other Aspergillus species evidence allowing breakpoint definitions is insufficient [77]. In the following only those studies are reviewed which have adopted these standards for the quantitation of minimal inhibitory concentrations (MICs). Data from routine susceptibility tests allowing a qualitative characterization of susceptible or resistant isolates only have not been considered.

As Natamycin is used nowadays for topical treatment of fungal infections only but no longer for systemic or oral treatment of fungal infections anymore, susceptible and resistant breakpoints have not been defined, so that by definition a quantitative measure for the characterization of a clinical isolate or a laboratory generated mutant as "Natamycin-resistant" is not existent. Furthermore, Natamycin has never been included into surveillance studies as it is used just for topical application, so that the question if a cross-resistance between Natamycin and Amphothericin B may exist amongst clinical isolates cannot be answered.

Although several longitudinal surveillance studies like the global SENTRY Antimicrobial Surveillance Program or ARTEMIS Global Antifungal Surveillance Program were and still are being conducted, information on the Amphothericin B susceptibility pattern is scarce as this polyene is not routinely included into these programs.

The SENTRY study revealed that in 2003 only $9.5 \%$ and $11.5 \%$ of Aspergillus spp. and A. fumigatus strains, respectively, isolated from infected, normally sterile body sites of hospitalized patients were inhibited at $<1 \mathrm{mg} / \mathrm{L}$ of Amphothericin B. Concentrations inhibiting $50 \%$ (MIC 50) of the C. albicans; $C$ parapsilosis, $C$. glabrata, $C$. tropicalis, and $C$. neoformans strains isolated from normally sterile body sites of hospitalized patients in North America, Europe, and Latin America amounted unifromly to $1 \mathrm{mg} / \mathrm{L}$, so that based on breakpoint definitions $50 \%$ of the isolates have to be classified as nonsusceptible [78]. Data generated three- and five years later in Northand Latin-America, Europe, and the Asia-Pacific region were not significantly different; in a few Candida species a decrease of MIC50 values by one titration step was noted and $71.4 \%$ of the $A$. fumigatus isolates were inhibited by $<1 \mathrm{mg} / \mathrm{L}$ Amphothericin B, Table $2[79,80]$. Analoguous data were generated in the course of the ARTEMIS study 
Page 4 of 10

$[81,82]$. Fifty percent of the $C$. glabrata [81] and C. krusei [82] isolates studied were inhibited at $1 \mathrm{mg} / \mathrm{L}$. A german/austrian multicenter study revealed that $11.3 \%$ of all Candida spp. isolates was resistant to Amphothericin B, $1.8 \%$ showing a complete cross-resistance to Azoles [83].

\begin{tabular}{|c|c|c|c|c|c|c|c|}
\hline Species & Range & MIC50 & MIC90 & \%res. & Region & Year & Ref. \\
\hline Candida spp. & $0.25-2$ & 1 & 1 & & \multirow{6}{*}{$\begin{array}{l}\text { SENTRY } \\
\text { global }\end{array}$} & \multirow{6}{*}{2003} & \multirow{6}{*}{78} \\
\hline C. albicans & $0.25-2$ & 1 & 1 & & & & \\
\hline C. glabrata & $0.25-2$ & 1 & 1 & & & & \\
\hline C. krusei & 2-Jan & 1 & 1 & & & & \\
\hline $\begin{array}{l}\text { Aspergillus } \\
\text { spp. }\end{array}$ & 4-Jan & 2 & 4 & & & & \\
\hline A. fumigatus & 16-Jan & 2 & 4 & & & & \\
\hline Candida spp. & $012-2$ & 0.5 & 1 & & \multirow{6}{*}{$\begin{array}{l}\text { SENTRY } \\
\text { global }\end{array}$} & \multirow{6}{*}{$\begin{array}{l}2006- \\
2007\end{array}$} & \multirow{6}{*}{79} \\
\hline C. albicans & $0.12-1$ & 0.5 & 1 & & & & \\
\hline C. glabrata & $0.12-1$ & 1 & 1 & & & & \\
\hline C. krusei & $0.12-2$ & 1 & 1 & & & & \\
\hline $\begin{array}{l}\text { Aspergillus } \\
\text { spp. }\end{array}$ & & & & & & & \\
\hline A. fumigatus & $0.12-2$ & 2 & 2 & & & & \\
\hline Candida spp. & $0.06-2$ & 0.5 & 1 & & \multirow{6}{*}{$\begin{array}{l}\text { SENTRY } \\
\text { global }\end{array}$} & \multirow{6}{*}{2008} & \multirow{6}{*}{80} \\
\hline C. albicans & $0.12-1$ & 0.5 & 1 & & & & \\
\hline C. glabrata & $0.25-1$ & 1 & 1 & & & & \\
\hline C. krusei & $0.25-1$ & 1 & 1 & & & & \\
\hline $\begin{array}{l}\text { Aspergillus } \\
\text { spp. }\end{array}$ & & & & & & & \\
\hline A. fumigatus & $0.25-1$ & 0.5 & 1 & & & & \\
\hline C. glabrata & $0.06-16$ & 1 & 2 & & \multirow{2}{*}{$\begin{array}{l}\text { ARTEMIS } \\
\text { global }\end{array}$} & 2002 & 81 \\
\hline C. krusei & $0.03-16$ & 2 & 2 & & & $\begin{array}{l}2001- \\
5\end{array}$ & 82 \\
\hline Candida spp. & & & & 11.3 & 1) & & 83 \\
\hline C. albicans & $0.016-1$ & 0.25 & 0.5 & & \multirow{3}{*}{ Denmark } & & \multirow{3}{*}{84} \\
\hline C. glabrata & $0.016-4$ & 0.5 & 1 & 1.6 & & & \\
\hline C. krusei & $0.016-4$ & 1 & 1 & 4.7 & & & \\
\hline C. glabrata & $0.25-2$ & 1 & 2 & & Iran & & 85 \\
\hline C. albicans & $0.25-2$ & 0.5 & 1 & & \multirow{3}{*}{ Brasil } & \multirow{3}{*}{2015} & \multirow{3}{*}{86} \\
\hline C. glabrata & 2-Jan & & & & & & \\
\hline C. krusei & 2-Jan & & & & & & \\
\hline Candida spp. & & & & 7.8 & India & & 87 \\
\hline C. tropicalis & & & & 17.6 & India & & 88 \\
\hline
\end{tabular}

\begin{tabular}{|l|l|l|l|l|l|l|l|}
\hline C. albicans & & & & 3 & UK & & 90 \\
\hline
\end{tabular}

Table 2: Amphothericin B susceptibility pattern for Candida species expressed as minimal inhibitory concentrations (MIC) inhibiting either $50 \%$ (MIC50) or $90 \%$ (MIC90) of the strains tested (\% res. $=\%$ resistance, i.e. amphothericin $\mathrm{MIC}>1 \mathrm{mg} / \mathrm{L} ; \quad$ Ref $=$ reference; 1) $=$ Germany/Austria).

Danish fungemia isolates of seven different Candida species collected over a five year period from 2004 to 2009 tended to be by one to two dilution steps more susceptible [84] than those collected in North- or Latin America and Europe in the course of the SENTRY study. But nevertheless, $1.6 \%$ of the $C$. glabrata and $4.7 \%$ of the $C$. krusei as well as $16.3 \%$ of the non-Candida isolates had to be classified as Amphothericin B resistant, Table 2 [84]. These representative longitudinal nationwide studies or international surveillance programs revealed that a significant number of clinical isolates were inhibited by Amphothericin B concentrations higher than the susceptible breakpoint of $1 \mathrm{mg} / \mathrm{L}$. A nationwide study in Iran demonstrated that the geometric mean MIC of Amphothericin B for C. glabrata was 1.1 $\mathrm{mg} / \mathrm{L}$ with a resistance rate of $27.5 \%$ [85]. Furthermore, point prevalence studies in Brazil [86] and India [87,88] demonstrated that Amphothericin B resistance among Candida spp. isolated from hospitalized patients in tertiary care hospitals amounted to $12.7 \%$ [86] and $7.8 \%$ to $17.5 \%[87,88]$, respectively. Other studies indicated that Amphothericin B resistance remained rare $[40,89,90]$. Candida spp.strains being simultaneously azole- and Amphothericin B-resistant due to loss-of-function mutations in ERG3 have been isolated, too [91-98].

In general, data quoted above demonstrate that a significant number of strains of various Candida species and A. fumigatus were inhibited by Amphothericin B concentrations which exceed the susceptible breakpoint and that a significant number of strains was isolated which were resistant to Amphothericin B as well as Azoles. Surveillance studies cannot be correlated with clinical outcome and therapeutic success or failure indicating that in vitro susceptibility testing alone is not sufficient to predict clinical efficacy of these antifungal agents [97]. However, this aspect is not relevant in the context of the use of a polyene as a food preservative hypothetically exerting a resistanceselective pressure on fungal populations harbouring polyene- and/or azole-resistance.

\section{Polyene Resistance Recovered from Patients Treated either with Amphothericin B or Natamycin as well as Patients not Having been on Antifungal Therapy}

It has long been documented that polyene-resistance emerged under therapy of immunosuppressed patients with Amphothericin B [99-107]. Recently, C. albicans strains were isolated consecutively from biopsies and faeces of an immunocompromised patient which acquired stepwise resistances to Azoles, Echinocandins, and Amphothericin B [108]. The gastrointestinal tract and central venous catheters were identified as sources of Candidal sepsis in these cases of disseminated candidemia [109]; in general, the gastrointestinal tract is the reservoir for Candida spp. Infections [110,111].

Polyene-resistant strains could not only be isolated from immunocompromised patients but from almost healthy, immunocompetent individuals as well [36]. Oral treatment of gastrointestinal Candida spp. colonization with $400 \mathrm{mg}$ Natamycin for ten days in 356 colonized patients resulted in a reduction in 
Page 5 of 10

susceptibility to Natamycin during exposure to this agent as compared to the susceptibilities of pre- and post-treatment isolates. Strains with Natamycin MICs of $1.25 \mathrm{mg} / \mathrm{L}$ could be isolated from $56 \%$ of these subjects prior to dosing, but from only $33 \%$ during exposures, and again $51 \%$ five days after cessation of therapy and $60 \%$ three months later [112]. Thus, the reduction of Natamycin-susceptibilities is a drugexposure related pharmacodynamic effect. This phenomenon supports the notion that exposure to Natamycin bears a resistance-selective potential. Also, Candida spp. isolated from women with vaginal candidosis was less susceptible to Natamycin than isolates from healthy women [113]. Although the authors did not describe that the fresh clinical isolates were withdrawn from Natamycin treated patients, data demonstrate that strains with reduced susceptibilities could be isolated. Natamycin MICs of $15 \mathrm{mg} / \mathrm{L}$ and $>50 \mathrm{mg} / \mathrm{L}$ were determined for two out of eight $C$. albicans strains freshly isolated from vaginal specimens (range 5 to $>50 \mathrm{mg} / \mathrm{L}$ ) as compared to a previously reported values of 3-6 mg/L [113].

Unfortunately, no systematic studies have been performed so far on the effect of polyenes on the gastrointestinal flora, so that the question if gastrointestinal $C$. albicans or other Candida spp. may harbour polyene resistance mechanisms can currently not be answered. But the studies quoted above clearly demonstrate that polyene-resistant strains of Candida spp. could be isolated from patients.

\section{Environmental Sources of Amphothericin B Resistant Fungi}

It is well documented that azole-resistance has been selected in environmental fungi due to their agricultural use and evidence has been presented that azole-resistant strains could be isolated from environmental samples as well from azole-naïve- and azole treated patients $[7,8]$. These strains were not only azole-resistant, but some of them were resistant to Amphothericin B, too. In one study, samples were taken from outdoor air across the province of Madrid, from hospital air, and from hospitalized patients being on antifungal therapy or not. MIC50- and MIC90-values, geometric means and ranges of MICs of Amphothericin B were almost identical for all the strains studied irrespective of their origin. MIC90-values for A. fumigatus isolated from patients being on antifungal therapy or not taking any antimycotics amounted uniformly to $2 \mathrm{mg} / \mathrm{L}$ [114]. This finding indicates that patients infected with Amphothericin B-resistant $A$. fumigatus may likely have been colonized from the environment. In agreement with this study, another study revealed that in Spain and Austria environmental Amphothericin B resistant A. fumigatus strains could be isolated [8]. Hence, it is not surprising that almost all strains of $A$. fumigatus, $A$. flavus and $A$. terreus isolated from the air sac of falcons were Amphothericin B resistant [115,116]. As reviewed recently, resistance mechanisms were identical in environmental as well as clinical isolates, thus strongly suggesting that the mutation in the clinical isolate has been acquired from an environmental strain [98]. Also, many potentially human pathogenic fungal species have their natural habitat in the environment [117], and fungal spores are spread over long distances by circulating air flows [98], so that potential pathogens and antifungal resistances may originate from the environment.

These findings demonstrate that Amphothericin B resistance and resistance to both, polyenes and Azoles, in environmental fungi seems to be widespread.

\section{Cross Resistance, Multidrug Resistance, and Horizontal Gene Transfer}

Data summarized above demonstrate that strains resistant to both, polyenes and Azoles could be isolated from environmental as well as clinical sources. Therefore, the question is, if Natamycin may exert a resistance-selective potential. One study has demonstrated that polyene-resistance induced by Amphothericin B or Nystatin lead to cross-resistance to Natamycin [42]. Likewise, a Nystatin-resistant isolate of Candida stellatoidea was also resistant to Amphothericin $A$, Amphothericin $B$, endomycin, filipin and Natamycin $[45,118]$. Molzahn and Woods [119] described that Natamycin selected for cross-resistance to Nystatin, but vice versa, Nystatin did not select for Natamycin-resistance in $S$. cerevisiae, these authors had not included Amphothericin B into the study. Phenotypically Natamycin- and Amphothericin B cross-resistant strains have been described [120]. Efficacy of both polyenes in a Candida keratitis model was directly correlated to their MICs, i.e. low MICs were associated with high reductions of viable counts and vice versa [120].

Not only polyenes, but chemically unrelated drug classes like Azoles select for polyene-resistance, too. Polyenes like Amphothericin B exert their fungicidal activity by binding to Ergosterol, followed by channel formation that further increases their activity. Natamycin interacts with Ergosterol without forming ion-channels, but it impairs membrane fusion via perturbation of Ergosterol-dependent priming reactions that precede membrane fusion [121-124]. Azoles disturbe fungal cell membrane sterol composition by inhibiting demethylation of Lanosterol and in the late step of Ergosterol biosynthesis also the desaturation of the sterol moiety, encoded by genes ERG11 and ERG 5 [125]. Several mechanisms have been documented to be involved in the resistance to Azoles as well as polyenes. They include active efflux, target enzyme alterations or its absence [126-129]. Amino acid alteration in the target enzyme ERG11 or the replacement of Ergosterol by other sterols in the membrane encoded by ERG3 are examples. As Ergosterol being essential for the mode of action of Azoles as well as polyenes is absent in ERG3 loss-of-function mutants, these strains escape the antifungal effect of both drug classes [91-98]. Other ERGgene defects also confer multi-drug-resistance [98]. Alterations in sterol- and phospholipid composition as well as changes in membrane structure account for different polyene-cross-resistance patterns $[130,131]$ and were found in clinical isolates resistant to Azoles as well as polyenes $[98,132-137]$. The situation is probably aggravated by the finding that a mutator phenotype caused by a mismatch repair defect is prevalent in C. glabrata [138]. This genetic mechanism promotes the acquisition of resistance to multiple antifungals. Strains carrying alterations in mismatch repair exhibit a higher propensity to breakthrough antifungal infections than non-mutator strains. Mutator strains were recovered at a rate as high as $55 \%$ from patients [128] thus giving rise to concern. Thus, Azoles as well as polyenes trigger resistance development in environmental and clinical fungal isolates as both drug classes share some common resistance mechanisms.

It could be argued that a colonization of a patient with a resistant strain acquired from the environment or hospital may probably not represent a hazard as many pathogenic yeasts are asexual and therefore not involved in intra- or interspecies exchanges of genes, i.e. horizontal gene transfer (HGT). Therefore, it has been concluded that resistance traits will not occur in fungi and an explosive expansion of resistance is unlikely to occur [139]. However, intra and interspecies gene transfers within fungi and even between bacteria and fungi have been described [140-149]. In principle, HGT could play an important role in the 
spread of resistance mechanisms between food-borne and pathogenic yeasts [148] as well as amongst fungi residing in the gastrointestinal tract. The interspecies exchange of plasmids harbouring resistance genes could be demonstrated in vitro [148], and secretion systems conferring drug-resistance could be transferred from bacteria to fungi $[150,151]$. These examples demonstrate that in principle a horizontal transfer of resistance genes within and between fungal species is possible.

\section{Discussion}

Clearly, the question "if the use of the polyene macrolide Natamycin as a food-additive may foster emergence of polyene-resistance development in Candida species" is a hypothetical question as the potential of Natamycin to select for polyene cross resistance in general or Amphothericin B resistance in particular has never been addressed systematically. This may be due to three reasons: first, susceptibility criteria allowing the classification of a strain as "Natamycinsusceptible" or "Natamycin-resistant" have never been defined; second, systematic studies on the propensity for resistance development in environmental and pathogenic strains have never been performed, and third, the European Food Safety Authority concluded that there was no concern for the induction of Natamycin-resistance [152] based on surveys in cheese warehouses and in dry sausage factories [50-52] as well as the difficult induction of Natamycin-resistant mutants in fungi [42]. However, aerogenic exposure of environmental fungi somewhere in distant vicinities of the production facility during the surface treatment of cheese or sausage to microbiologically active concentrations of a light unstable Natamycin formulation is very unlikely, so that this finding does not appear to be particular pertinent. Above all, different Natamycin formulations are in use either for surface treatment of cheese and sausages, or preservation of yoghurt, wine, beverages, etc. In principle, Natamycin is preferable to many other preservatives as it is free from odour and colour so that it causes no taste perversion and therefore does not adversely affect consumer acceptance. Because of its light- and acid instability, Natamycin will be degraded on the surfaces of cheese and sausages by the time of purchase by the consumer, so that the consumer will be exposed to negligibly low concentrations of Natamycin, if at all. Because of these characteristics and a favourable safety profile the Joint Food and Agriculture Organization of the United Nations and World Health Organization Expert Committee on Food Additives (JECFA) regarded the use of Natamycin for surface treatment of cheese and sausages as safe for human use [153]. However, a new light- and acid stable slow release formulation reducing inactivation of Natamycin for several weeks has been developed [29,30] for the preservation of yoghurt, wine, and beverages. Natamycin concentrations in food containing this new formulation range from $5-10 \mathrm{mg} / \mathrm{kg}$ yoghurt to $30 \mathrm{mg} / \mathrm{L}$ wine. Furthermore, Natamycin has been formulated as a cyclodextrin inclusion complex as it is barely soluble in beverages. Soluble concentrations of the conventional formulation are much lower than needed for a preservation of the product till the end of its shelf life, but this cyclodextrin inclusion formulation allows the production of beverages containing up to $500 \mathrm{mg} / \mathrm{L}$ of solubilized Natamycin (reviewed in 36). Thus, different Natamycin formulations are used for surface treatment of cheese and sausages on the one hand and preservation of yoghurt or wine on the other hand; the formulations differ from each other in stability- and solubility, and thus probably also in their pharmacological- and/or toxicological profiles. Also, the consumer is either not exposed to Natamycin because of its instability to light and acid, or will be exposed to Natamycin concentrations ranging from $3.33 \mathrm{mg} / \mathrm{kg}$ to $6.66 \mathrm{mg} / \mathrm{kg}$ faeces following consumption of $100 \mathrm{~g}$ of yoghurt containing either $5 \mathrm{ppm}$ or $10 \mathrm{ppm}$ Natamycin, $19.98 \mathrm{mg} / \mathrm{kg}$ of faeces following consumption of one litre of wine containing $30 \mathrm{mg} / \mathrm{L}$, or maximally $3,333.0 \mathrm{mg} / \mathrm{kg}$ faeces following consumption of $1 \mathrm{~L}$ of beverage containing $500 \mathrm{mg}$ of a Natamycin cyclodextrin-complex [36] provided the entire amount of Natamycin consumed with yoghurt or wine is deposited in the faeces and is freely available.

Faecal Natamycin concentrations are within the microbiologically active range. As summarized above, fungi developed polyeneresistance upon long term in vitro exposure to sub-inhibitory Natamycin concentrations, a finding which is supported by two observational clinical studies. Polyene-resistance seems to be ubiquitous in the environment as well as in hospitals, probably also due to the use of Azoles in agriculture selecting for polyene-resistance, too, so that even antimycotic naïve patients may be colonized with polyeneresistant fungal pathogens. Consumption of Natamycin containing food may thus exert a polyene-resistance selective pressure.

The use of Natamycin as a food preservative confronts us with a paradox. On the one hand use of antibiotics as growth promotors in food producing animals has been banned in 2006, and action plans have been put forward aiming at a mitigation of the risk of antibiotic resistance development, so that maximal residue levels in food animals and withdrawal times to reduce drug concentrations below levels safe for human consumption have been defined both in the US and the EU $[154,155]$. Maximal residue levels of most antibacterials in edible tissue range in the US from 0.1 to $0.01 \mathrm{ppm}$ [156]. To define if drug levels are safe for human consumption, the probabilities have to be assessed that first, bacteria in the animal population will acquire resistance, second, that humans will ingest the resistant bacteria in food products, and third, that ingesting the bacteria will result in adverse health outcomes [157]. Consequently, this is an indirect and an unquantified hazard as not drug residues but resistance genes of microbial origin may be transferred from animals to humans via the food chain. However, addition of Natamycin to food may expose the human resident flora directly and quantifiably to a selective pressure. If Natamycin in itself may cause emergence of polyene-resistance in the gastrointestinal fungal flora and/or may act as an Amphothericin B resistance selector may be probable but is speculative. But still, the reservoir of Amphothericin B resistant fungal species should not be enlarged by an inappropriate use of antifungals in general and of polyenes in particular. Clinical efficacy of Amphothericin B should be preserved as it is used to treat serious, life threatening infections. Therefore, the use of any anti-infective agent as a food-preservative should be limited to an absolute minimum.

\section{Declaration of Interest}

The author has received financial support from MerLion Pharmaceuticals, Berlin, DE; Morphochem AG for Combinatorial Chemistry, Munich, DE; Cerexa Inc., Oakland, CA, USA; MorphoSys AG, Martinsried, DE; Eumedica SA, Manage, BE; Vetoquinol, Lure Cedex, FR; Wockhardt Ltd., Mumbai, IND; Astra-Zeneca, London, UK; Bayer AG, Leverkusen, DE.

\section{Funding Source}

The preparation of the article has been supported by a grant from LanXess Deutschland GmbH, Kennedyplatz 1,50569 Köln, Germany. 
The funders had no role in data collection, analysis and interpretation, or the decision to submit the article for publication.

\section{References}

1. Silva MM, Lidon FC (2016) Food preservatives - an overview on applications and side effects. Emir J Food Agric 28: 366-373.

2. Witte W (2000) Selective pressure by antibiotic use in livestock. J Antimicrob Agents 16: 19-24.

3. Tello A, Austin B, Telfer TC (2012) Selective pressure of antibiotic pollution on bacteria of importance to public health. Environ Health Perspect 120: 1100-1106.

4. Enserink M (2009) Farm fungicides linked to resistance in a human pathogen. Infect dis 326: 1173 .

5. Anonymos. EU Medicines Agency Network Strategy to 2020- Working together to improve health. EMA/20112/2015.EMA/MB/ 151414/2015.http://www.ema.europa.eu/docs/en_GB/document_library/ Other/2015/12/WC500199060.pdf

6. Verweij PE, Sneiders E, Kema GJH, Mellado E, Melchers WJG (2009) Azole resistance in Aspergillus fumigatus: a side-effect of environmenta fungicide use? Lancet Infect Dis 9: 789-795.

7. Snelders E, Rijs AJ, Kema GH, Melchers WJ, Verweij (2009) P.E. Possible environmental origin of resistance of Aspergillus fumigatus to medical triazoles. Appl Environm Microbiol 75: 4053-4057.

8. Mortensen KL, Mellado E, Lass-Flörl C, Rodriguez-Tudela JL, Jonahsen HK, et al. (2010) Environmental study of azole-resistant Aspergillus fumigatus and other Aspergilli in Austria, Denmark, and Spain. Antimicrob Agents Chemother 54: 4545-4549.

9. Bader O, Tünnermann J, Dudakova A, Tangwattanachuleeporn M, Weig $\mathrm{M}$, et al. (2015) Environmental isolates of azole-resistant Aspergillus fumigatus in Germany. Antimicrob Agents Chemother 59: 4356-4359.

10. Sharma C, Hagen F, Moroti R, Meis JF, Chowdhary A (2015) Triazoleresistant Aspergillus fumigatus harbouring G54 mutation: Is it de novo or environmentally acquired? J Glob Antimicrob Res 3: 69-74.

11. Chowdhary A, Kathuria S, Xu J, Meis JF (2013) Emergence of azoleresistant Aspergillus fumigatus strains due to agricultural azole use creates an increasing threat to human health. PLoS Pathog 9: e1003633.

12. Medeiros AO, Kohler LM, Hamdan JS, Missagia BS, Barbosa FAR, et al. (2008) Diversity and antifungal susceptibility of yeasts from tropical freshwater environments in Southeastern Brazil. Water Res 42: 39213929.

13. Brilhante RSN, Paiva MAN, Sampaio CMS, Castelo BDSCM, Alencar LP, et al. (2015) Surveillance of Azole Resistance Among Candida spp. as a Strategy for the Indirect Monitoring of Freshwater Environments. Water Air Soil Pollut 226: 52.

14. Azevedo MM, Faria RI, Cruz LC, Pina-Vaz C, Rodriguez AC (2015) Genesis of Azole Antifungal Resistance from Agriculture to Clinical Settings. J Agric Food Chem 63: 7463-7468.

15. Prigitano A, Venier V, Cogliati M, De Lorenzis G, Esposto MC, et al. (2014) Azole-resistant Aspergillus fumigatus in the environment of northern Italy. Euro Surveill. 19: 20747.

16. Young NWG, O'Sullivan GR (2011) The influence of ingredients on product stability and shelf life. In: Kilcast D, Subramaniam P (Eds.): Food and beverage stability and shelf life. Woodhead Publishing Ltd pp 132-183.

17. Anonymos, Technology Science Group Inc. Petition for classification of natamycin as an allowed substance in organic crop production.

18. Environmental protection agency 40 CFR Part 180 (EPA-HQ-OPP2015-0811; FRL-9949-03) Natamycin; Exemption From the Requirement of a Tolerance.

19. Dekker A, Dutreux NL, Stark J (2005) Polyene antibiotic for controlling fungal growth in banana crops.

20. Stark J, Van RFTJ, Van der KWM, Stevens LH (2009) Treatment of banana and potatoe plants with a new antifungal composition.
21. Stark J, Van Rijn FTJ, Van der KWM, Stevens LH (2009) A new antifungal composition.

22. Sandmeier D, Kensbrock E (2015) Method for producing an antimicrobial coating on a technical surface.

23. Cerqueira MA, Costa MJ, Fucinos C, Pastrana LM, Vicente AA (2014) Development of active and nanotechnology-based smart edible packing systems: physical-chemical characterization. Food Bioprocess Technol 7: 1472-1482.

24. Stark J (2000) Permitted preservatives-natamycin. Encyclopedia of food microbiology 3: 1776-1781.

25. Van Rijn FTJ, Stark J (2004) Stable aqueous solution of natamycin fungicide.

26. De Haan BR, Van Rijn FTJ (2006) Stable needle shaped crystals of natamycin.

27. GRAS Notice Inventory. US Food and Drug Administration.

28. Food standards \& safety - standards development - Application A1095 Natamycin - Extension of use in yoghurt - Working file - Pt2 FSANZPSS. File No 2014/006436.

29. Van Rijn FTJ, Wildeboer WJ (2012) Anti-fungal composition. United States Patent US 8,187,844 B2.

30. Van Rijn FTJ, Wildeboer WJ (2013) Anti-fungal composition. United States Patent US 8,536,144 B2.

31. Dervisoglu M, Gul O, Aydemir O, Yazci F, Kahyaoglu T (2014) Natamycin content and quality evaluation of yoghurt fromsmall- and large-scale brands in Turkey. Food Addit Contam Part B Surveill 7: 254-260.

32. Bilgic ADI, Karalomlu O (2016) Determination of Natamycin in Turkish Yoghurt. Int J Anal Chem 2016: 8480963.

33. Fahim NK, Beheshti HR, Feizy J, Janati SSF (2012) LC determination of natamycin in doogh with UV detection. GIDA (Gida Teknolojisi Derne.i Yayini) 37: 127-132.

34. Dzigbordi B, Adubofuor J, Faustina D (2013) The effects of different concentrations of natamycin and the point of addition on some physicochemical and microbial properties of vanilla flavoured yoghurt under refrigerated condition. Int Food Res J 20: 3287-3292.

35. Sara AE, Ekbal MA, Adham MA, Hamdi AM (2014) The role of natamycin fortification to extend shelf life of plain yoghurt. Benha Vet Med J 27: 140-149.

36. Dalhoff AA, Levy SB (2015) Does use of the polyene natamycin as a food preservative jeopardise the clinical efficacy of amphotericin B? A word of concern. Int J Antimicrob Agents 45: 564-567.

37. Streekstra H, Keuter A, Wilms L (2015) Reaction to Dalhoff and Levy: 'does use of natamycin as a food preservative jeopardise the clinical efficacy of amphotericin B? A word of concern. Int J Antimicrob Agents 46: 595-596.

38. Dalhoff A (2015) Response to the reaction to Dalhoff and Levy: Does use of the polyene natamycin as a food preservative jeopardise the clinical efficacy of amphotericin B? A word of concern. Int J Antimicrob Agents 46: 596-597.

39. Streekstra H, Verkennis AE, Jacobs R, Dekker A, Stark J, et al. (2016) Fungal strains and the development of tolerance against natamycin. Int J Food Microbiol 238: 15-22.

40. Knechtel SA, Klepser ME (2007) Amphothericin B resistance: epidemiology, mechanisms, and clinical relevance. J Invasive Fungal Infect 1: 93-98.

41. Office of Food Additive Safety (HFS-200), Center for Food Safety and Applied Nutrition (CFSAN), Food and Drug Administration, by DSM Food Specialties B.V. GRAS notification for the use of natamycin in yogurt. Submitted to: Office of Food Additive Safety (HFS-200), Center for Food Safety and AppliedNutrition (CFSAN), Food and Drug Administration, by DSM Food Specialties B.V; 2015.

42. Athar MA, Winner HI (1971) The development of resistance by candida species to polyene antibiotics in vitro. J Med Microbiol 4: 505-517.

43. Littman M, Pisano M, Lancaster R (1957) Induced resistance of Candida species to nystatin and amphotericin B. Antibiot Annu 5: 981-987. 
44. Hebeka Ek, Solotorovsky M (1962) Development of strains of Candida albicans resistant to candidin. J Bacteriol 84: 237-241.

45. Hebeka Ek, Solotorovsky M (1965) Development Of Resistance To Polyene Antibiotics In Candida Albicans. J Bacteriol 89: 1533-1539.

46. Lones GW, Peacock CL (1959) Alterations in Candida albicans during growth in the presence of amphothericin B. Antibiot Chemother 9: 535-540.

47. Sorensen LJ, McNall EG, Sternberg TH (1958-1959) The development of strains of Candida albicans and Coccidiodes immitis, which are resistant bto amphothericin B. Antibiot Annu 6: 920-923.

48. Dittrich HH, Sponholz WR (1981) Über Resistenzbildung und morphologische Veränderungen bei Hefen nach Anwendung von Natamycin. Wein-Wissenschaft 36: 431-436.

49. Pagano Jf, Stout Ha (1955) Resistance studies with nystatin. Antibiot Annu 3: 704-710.

50. de Boer E, Stolk-Horsthuis M (1977) Sensitivity to natamycin (pimaricin) of fungi isolated in cheese warehouses. J Food Prot 40: 533-536.

51. de Boer E, Labots H, Stolk-Horsthuis M, Visser JN (1979) Sensitivity to natamycin of fungi in factories producing dry sausage. Fleischwirtschaft 59: 1868-1869.

52. Hoekstra ES, Van der Horst MI (1998) Survey of the fungal flora in Dutch cheese factories and warehouses. J Food Mycol 1: 13-22.

53. Shapiro RS, Robbins N, Cowen LE (2011) Regulatory circuitory governing fungal development, drug resistance, and disease. Microbiol Mol Biol Rev 75: 213-267.

54. Cowen LE, Steinbach WJ (2008) Stress, drugs, and evolution: the role of cellular signalling in fungal drug resistance. Eucaryot Cell 7: 747-764.

55. Zhang L, Zhang Y, Zhou Y, An S, Zhou Y, et al. (2002) Response of gene expression in Saccharomyces cerevisiae to amphothericin B and nystatin by microarrays. J Antimicrob Chemother 49: 905-915.

56. Agarwal AK, Rogers PD, Baerson SR, Jacob MR, Barker KS, et al. (2003) Genome-wide expression profiling of the response to polyene, pyrimidine, azole, and echinocandin antifungal agents in Sacchoromyces cerevisiae. J Biol Chem 278: 34998-35015.

57. Barker KS, Crisp S, Wiederhold N, Lewis RE, Bareither B, et al. (2004) Genome-wide expression profiling reveals genes associated with amphothericin B and fluconazole resistance in experimentally induced antifungal resistant isolates of Candida albicans. J Antimicrob Chemother 54: 376-385.

58. Liu TT, Lee REB, Barker KS, Lee RE, Wei L, et al. (2005) Genome-wide expression profiling of the response to azole, polyene, echinocandin, and pyriridine antifungal agents in Candida albicans. Antimicrob Agents Chemother 49: 2226-2236.

59. Yu L, Zhang W, Wang L, Yang J, Liu T, et al. (2007) Transcriptional profiles of the response to ketoconazole and amphothericin $\mathrm{B}$ in Trichophyton rubrum. Antimicrob Agents Chemother 51: 144-153.

60. Cannon RD, Lamping E, Holmes AR, Niimi K, Tanabe K, et al. (2007) Candida albicans drug resistance another way to cope with stress. See comment in PubMed Commons below Microbiology 153: 3211-3217.

61. Gautam P, Shankar J, Madan T, Sirdeshmukh R, Sundaram CS, et al. (2008) Proteomic and transcriptomic analysis of Aspergillus fumigatus on exposure to amphothericin B. Antimicrob Agents Chemother 52: 4220-4227.

62. Hoehamer C, Cummings ED, Hilliard GM, Rogers PD (2010) Changes in the proteome of Candida albicans in response to azole, polyene, and echinocandin antifungal agents. Antimicrob Agents Chemother 54: 1655-1664.

63. Cohen BE (2010) Amphotericin B membrane action: role for two types of ion channels in eliciting cell survival and lethal effects. J Membr Biol 238: $1-20$.

64. Cohen BE (2014) Functional linkage between genes that regulate osmotic stress eresponses and multidrug resistance transporters: challenges and opportunities for antibiotic discovery. Antimicrob Agents Chemother 58: 640-646.
65. Teixeira-Santos R, Ricardo E, Guerreiro SG, Costa-de-Oliveira S, Rodriguez AG, et al. (2015) New insights regarding yeast survival following exposure to liposomal amphothericin B. Antimicrob Agents Chemother 59: 6181-6187.

66. Valiante V, Macheleidt J, Föge M, Brakhage AA (2015) The Aspergillus fumigats cell wall integrety signalling pathway: drug target, compensatory pathways, and virulence. Front Microbiol 6: 325.

67. Cohen BE (2016) The Role of Signaling via Aqueous Pore Formation in Resistance Responses to Amphotericin B. Antimicrob Agents Chemother 60: 5122-5129.

68. Cuenca-Estrella M, Lee-Yang W, Ciblak MA, Arthington-Skaggs BA, Mellado E, et al. (2002) Comparative evaluation of NCCLS M27-A and EUCAST broth microdilution procedures for antifungal susceptibility testing of Candida species. Antimicrob Agents Chemother 46: 3644-3647. 69. CLSI (2008). Reference Method for Broth Dilution Antifungal Susceptibility Testing of Yeasts; 3rd edn, M27-A3. Wayne, PA: Clinical and Laboratory Standards Institute. ISBN: 1-56238-666-2.

69. CLSI (2008a). Reference Method for Broth Dilution Antifungal Susceptibility Testing of Yeasts; 3rd edn, M27-A3. Wayne, PA: Clinical and Laboratory Standards Institute.

70. CLSI (2008b). Reference Method for Broth Dilution Antifungal Susceptibility Testing of Yeasts; 3rd edn, Informational Supplement M27S3. Wayne, PA: Clinical and Laboratory Standards Institute.

71. CLSI (2012). Reference Method for Broth Dilution Antifungal Susceptibility Testing of Yeasts; 4th informational supplement M27-S4. Wayne, PA: Clinical and Laboratory Standards Institute. ISBN: 1-56238-864-9.

72. Arendrup MC, Estrella CM, Lass-Flörl C, Hope W (2012) EUCAST technical note on the EUCAST definitive document EDef 7.2: method for the determination of broth dilution minimum inhibitory concentrations of antifungal agents for yeasts EDef 7.2 (EUCAST-AFST). Clin Microbiol Infect 18: E246-E247.

73. Arendrup MC, Cuenca-Estrella M, Lass-Flörl C, Hope WW (2012) European Committee on Antimicrobial Susceptibility Testing Subcommittee on Antifungal Susceptibility Testing (EUCAST-AFST) EUCAST technical note on Aspergillus and amphotericin B, itraconazole, and posaconazole. Clin Microbiol Infect 18: E248-E250.

74. Lass-Flörl C, Arendrup MC, Rodriguez-Tudela JL, Cuenca-Estrella M, Donnelly P, et al. (2011) EUCAST technical note on Amphotericin B. Clin Microbiol Infect 17: E27-E29.

75. Estrella CM, Yang LW, Ciblak MA, Skaggs BA, Mellado E, et al. (2002) Comparative evaluation of NCCLS M27-A and EUCAST broth microdilution procedures for antifungal susceptibility testing of Candida species. Antimicrob Agents Chemother 46: 3644-3647.

76. European Committee on Antimicrobial Susceptibility Testing. Amphotericin B: Rationale for the clinical breakpoints, version 1.0, 2010.

77. European Committee on Antimicrobial Susceptibility Testing. Amphotericin B and Aspergillus spp.: Rationale for the clinical breakpoints, version 1.0, 2012.

78. Messer SA, Jones RN, Fritsche TR (2006) International surveillance od Candida spp. and Aspergillus spp: report from the SENTRY antimicrobial surveillance program. J Clin Microbiol 44: 1782-1878.

79. Messer SA, Moet GJ, Kirby JT, Jones RN (2009) Activity of contemporary antifungal agents, including the novel echiinocandin, tested against Candida spp., Cryptococcus spp., and Aspergillus spp.: report from the SENTRY antimicrobial surveillance program (2006 to 2007). J Clin Microbiol 47: 1942-1946.

80. Messer SA, Jones RN, Moet GJ, Kirby JT, Castanheira M (2010) Potency of anidulafungin compared to nine other antifungal agents tested against Candida spp., Cryptococcus spp., and Aspergillus spp.: results from the global SENTRY Antimicrobial Surveillance Program (2008). J Clin Microbiol 48: 2984-2987.

81. Pfaller MA, Messer SA, Boyken L, Tendolkar S, Hollis RJ, et al. (2004) Geographic $c^{\prime}$ variation in the susceptibilities of invasive isolates of candida glabrata to seven systemically active antifungal agents: a global 
assessment from the ARTEMIS antifungal surveillance program conducted in 2001 and 2002. J Clin Microbiol 42: 3142-3146.

82. Pfaller MA, Diekema DJK, Gibbs DL, Newell VA, Nagy E, et al. (2008) Candida krusei, a multidrug-resistant opportunistic fungal pathogen: geographic and temporal trends from the ARTEMIS DISK antifunfgal surveillance program, 2001 to 2005. J Clin Microbiol 46: 515-521.

83. Schmalreck AF, Willinger B, Idelevich EA, Fegeler C, Lass-Flörl C, et al. (2016) Parallel and cross-resistance of clinical yeast isolates determined by susceptibility pattern analysis. GMS Infect Dis 41/13-13/13.

84. Arendrup MC, Bruun B, Christensen JJ, Fuursted K, Johansen HK, et al. (2011) National surveillance of fungemia in Denmark (2004 to 2009). J Clin Microbiol 49: 325-334.

85. Amirrajab N, Badali H, Didehdar M, Afsarian MH, Mohammadi R, et al. (2016) In vitro activities of six antifungal drugs against Candida glabrata isolates: An Emerging Pathogen. Jundishapur J Microbiol 9: e36638.

86. Menezes RDP, Ferreira JC, Moreira TDA, Malvino LDS, Araujo LBD, et al. (2015) Frequency of Candida species in a tertiary care hospital in Triangulo Mineiro, Minas Gerais State, Brazil. Rev Inst Med Trop Sao Paulo 57:185-191.

87. Kaur R, Dhakad MS, Goyal R, Kumar R (2016) Emergence of nonalbicans Candida species and anti-fungal resistance in intensive care unit patients. Asian Pac J Trop Biomed 6: 455-460.

88. Deorukhkar SC, Saini S, Mathew S (2014) Virulence factors contributing to to pathogenicicty of Candida tropicalis and its antifungal susceptibility. Int J Microbiol Article ID 456878.

89. Sanglard D, Odds FC (2002) Resistance of Candida species to antifungal agents: molecular mechanisms and clinical consequences. Lancet Infect Dis 2: 73-85.

90. Anonymos Health protection report. Surveillance of Candidaemia in England, Wales, and Northern Ireland: 2015. Infection report Volume 10, Number 32, published on Septembver 23, 2016. Available at: https:// www.gov.uk/government/uploads/system/uploads/attachment_data/file/ 555332/hpr3216_cnddm.pdf

91. Eddouzi J, Parker JE, Vale-Silva LA, Coste A, Ischer F, et al. (2013) Molecular mechanisms of drug resistance in clinical Candida species isolated from Tunesian hospitals. Antimicrob Agents Chemother 57: 3182-3193.

92. Morio F, Pagniez F, Lacroix C, Miegeville M, Le Pape P (2012) Amino acid sub-stitutions in the Candida albicans sterol ?5,6-desaturase (Erg3p) confer azole resistance: characterization of two novel mutants with impaired virulence. J Antimicrob Chemother 67: 2131-2138.

93. Vincent BM, Lancaster AK, Shouval SR, Whitesell L, Lindquist S (2013) Fitness trade-offs restrict the evolution of resistance to amphotericin B. PLoS Biol 11: e1001692.

94. Martel CM, Parker JE, Bader O, Weig M, Gross U, et al. (2010) A clinical isolate of Candida albicans with mutations in ERTG11 (encoding sterol 14-alpha-demethylase) and ERG5 (encoding C22 desaturase) is cross resistant to azoles and amphothericin B. Antimicrob Agents Chemother 54: 3578-35883.

95. Sanglard D, Ischer F, Parkinson T, Falconer D, Bille J (2003) Candida albicans mutations in the ergosterol biosynthetic pathway and resistance to several antifungal agents. Antimicriob Agents Chmeother 47: 2404-2412.

96. Silva VLA, Coste AT, Ischer F, Parker JE, Kelly SL, et al. (2012) Azole resistance by loss of function of the sterol d5,6-desaturase gene (ERG3) in Candida albicans does not necessarily decrease virulence. Antimicrob Agents Chemother 56:1960-1968.

97. Kanafani ZA, Perfect JR (2008) Antimicrobial resistance: resistance to antifungal agents: mechanisms and clinical impact. Clin Infect Dis 46: 120-128.

98. Sanglard D (2016) Emerging Threats in Antifungal-Resistant Fungal Pathogens. Front Med (Lausanne) 3: 11.

99. Gheith S, Saghrouni F, Bannour W, Youssef YB, Khelif A, et al (2014) In vitro susceptibility to amphotericin B, itraconazole, voriconazole, posaconazole and caspofungin of Aspergillus spp. isolated from patients with haematological malignancies in Tunisia. Springerplus 3:19.
100. Rodloff C, Koch D, Schaumann R (2011) Epidemiology and antifungal resistance in invasive candidiasis. Eur J Med Res 16: 187-195.

101. Pahwa N, Kumar R, Nirkhiwale S, Bandi A (2014) Species distribution and drug sus-ceptibility of Candida in clinical isolates from a tertiary care centre at Indore. Indian J Med Microbiol 32: 44-48.

102. Sardi JDCO, Pitangui NDSP, Gullo FP, Giannini MJSMAMFA (2013) A mini review of Candida species in hospital infection:epidemiology, virulence factor and drugs resistance and prophylaxis. Trop MedSurg 1: 141.

103. Merz WG, Sandford GR (1979) Isolation and characterization of a polyene-resistant variant of Candida tropicalis. J Clin Microbiol 9: 677-680.

104. Dick JD, Merz WG, Saral R (1980) Incidence of polyene-resistant yeasts recovered from clinical specimens. Antimicrob Agents Chemother 18: 158-163.

105. Madsen MK, Arendrup MC, Heslet L, Knudsen JD (2006) Amphothricin B and caspofungin resistance in Candida glabrata isolates recovered from a critically ill patient. Clin Infect Dis 42: 938-944.

106. Powderly WG, Kobayashi GS, Herzig GP, Medoff G (1988) Amphotericin B-resistant yeast infection in severely immunocompromised patients. Am J Med 84: 826-832.

107. Antoniadou A, Torres HA, Lewis RE, Thronby J, Bodey GP, et al. (2003) Candidemia in a tertiary care cancer center. In vitro susceptibility and its association with outcome of initial antifungal therapy. Medicine 82: 309321.

108. Jensen RH, Astvad KMT, Silva LV, Sanglard D, Jorgensen R, et al. (2015) Stepwise emergence of azole, echinocandin, and amphothericin B multidrug resistance in vivo in Candida albicans orchestrated by multiple genetioc alterations. J Antimicrob Chemother 70: 2551-2555.

109. Blumberg EA, Reboli AC (1996) Failure of systemic empirical treatment with amphotericin B to prevent Candidemia in neutropenic patients with cancer. Clin Infect Dis 22: 422-426.

110. Donskey CJ (2004) The role of the intestinal tract as a reservoir and source for transmission of nosocomial pathogens. Clin Infect Dis 39: 219-226.

111. Yan L, Yang C, Tang J (2013) Disruption of the intestinal mucosal barrier in Candida albicans infections. Microbiol Res 168: 389-395.

112. Gehring W, Späte W, Gehse M, Gloor M, Braun K (1990) Results of a combination treatment with natamycin and butylscopolamine in cases of intestinal Candida colonization. Mycoses 33: 140-145.

113. Lövgren T, Salmela I (1978) In vitro sensitivity of Trichomonas vaginalis and Candida albicans to chemotherapeutic agents. Acta Pathol Microbiol Scand Sect B 86B: 155-158.

114. Guinea J, Pelaez T, Alcala L, Serrano RMJ, Bouza E (2005) Antifungal susceptibility of 596 Aspergillus fumigatus strains isolated from outdoor air, hospital air, and clinical samples: analysis by site of isolation. Antimicrob Agents Chemother 49: 3495-3497.

115. Silvanose C, Bailey TA, di Somma A (2011) In vitro sensitivity of Aspergillus species isolated from respiratory tract of falcons. Online veterinary journal; 6: article 95 .

116. Silvanose CD, Bailey TA, Di Somma A (2006) Susceptibility of fungi isolated from the respiratory tract of falcons to amphotericin $\mathrm{B}$, itraconazole and voriconazole. Vet Rec 159: 282-284.

117. Hof $\mathrm{H}$ (2001) Critical annotations to the use of azole antifungals for plant protection. Antimicrob Agents Chemother 45: 2987-2990.

118. Woodes RA, Ahmed KA (1968) Genetically controlled cross resistance to polyene antibiotics in Sacchoromyces cerevisiae. Nature 218: 369-370.

119. Molzahn SW, Woods RA (1972) Polyene resistance and the isolation of sterol mutants in Saccharomyces cerevisiae. J Gen Microbiol 72: 339-348.

120. O'Day DM, Ray WA, Robinson RD, Head WS (1987) Correlation of in vitro and in vivo susceptibility of Candida albicans to amphotericin B and natamycin. Invest Ophthalmol Vis Sci 28: 596-603.

121. Gray KC, Palacios DS, Dailey I, Endo MM, Uno BE, et al. (2012) Amphotericin primarily kills yeast by simply binding ergosterol. Proc Nat Acad Sci US 109: 2234-2239. 
122. te Welscher YM, Jones L, van Leeuwen MR, Dijksterhuis J, de Kruijff B, et al. (2010) Natamycin inhibits vacuole fusion at the priming phase via a specific interaction with ergosterol. Antimicrob Agents Chemother 54: 2618-2615.

123. Kato M, Wickner W (2001) Ergosterol is required for the Sec18/ATPdependent priming step of homotypic vacuole fusion. EMBO J 20 4035-4040.

124. te Welsche YM, ten Napel HH, Balague MM, Souza CM, Riezman H, et al. (2008) Natamycin blocks fungal growth by binding specifically to ergosterol without permeabilizing the membrane. J Biol Chem 283: 6393-6401.

125. Odds FC, Brown AJ, Gow NA (2003) Antifungal agents: mechanisms of action. Trends Microbiol 11: 272-279.

126. Perea S L, Ribot L, Kirkpatrick WR, McAtee RK, Santillan RA, et al. (2001) Prevalence of molecular mechanisms of resistance to azole antifungal agents in Candida albicans strains displaying high-level fluconazole resistance isolated from human immunodeficiency virusinfected patients. Antimicrob Agents Chemother 45: 2676-2684.

127. Sanglard D, Ischer F, Koymans L, Bille J (1998) Amino acid substi-tutions in the cytochrome P450 lanosterol 14-demethylase (CYP51A1) from azole-resistant Candida albicans clinical isolates contributing to the resistance to azole antifungal agents. Antimicrob Agents Chemother 42: 241-253.

128. Sanglard D, Kuchler K, Ischer F, Pagani JL, Monod M, et al. (1995) Mechanisms of resistance to azole antifungal agents in Candida albicans isolates from AIDS patients involve specific multidrug transporters. Antimicrob Agents Chemother 39: 2378-2386.

129. White TC, Marr KA, Bowden RA (1998) Clinical, cellular, and molecular factors that contribute to antifungal drug resistance. Clin Microbiol Rev 11: 382-402

130. Pierce AM, Pierce HD, Unrau AM, Oehlschläger AC (1978) Lipid composition and polyene antibiotic resistance of Candida albicans mutants. Canadian J Biochem 56: 135-142.

131. Broughton MC, Bard M, Lees ND (1991) Polyene resistance in ergosterol producing strains of Candida albicans. Mycoses 34: 75-83.

132. Kołaczkowska A, Kołaczkowski M (2016) Drug resistance mechanisms and their regulation in non-albicans Candida species. J Antimicrob Chemother 71: 1438-1450.

133. Hull CM, Parker JE, Bader O, Weig M, Gross U, et al. (2012) Facultative sterol uptake in an ergosterol-deficient clinical isolate of Candida glabrata harboring a missense mutation in ERG11 and exhibiting cross-resistance to azoles and amphotericin B. Antimicrob Agents Chemother 56: 4223-4232.

134. Eddouzi J, Parker JE, Coste A, Ischer F, Kelly S, et al. (2013) Molecular mechanisms of drug resistance in clinical Candida species isolated from Tunisian hospitals. Antimicrob Agents Chemother 57: 3182-3193.

135. Kelly SL, Lamb DC, Kelly DE, Manning NJ, Loeffler J, et al. (1997) Resistance to fluconazole and cross-resistance to amphotericin B in Candida albicans from AIDS patients caused by defective sterol ? 5,6desaturation. FEBS Lett 400: 80-82.

136. Schaffner A, Böhler A (1993) Amphotericin B refractory aspergillosis after itraconazole: evidence for significant antagonism. Mycoses 36: 421-424.

137. Horne JT, Hollomon D, Loeffler RS, Kelly SL (1995) Cross-resistance to polyene and azole drugs in Cryptococcus neoformans. Antimicrob Agents Chemother 39: 1526-1529.
138. Healy KR, Zhao Y, Perez WB, Lockhart SR, Sobel JD, et al. (2016) Prevalent mutator genotype identified in fungal pathogen Candida glabrata promotes multi-drug resistance. Nat Commun 7: 11128.

139. Hof H (2008) Is there a serious risk of resistance development to azoles among fungi due to the widespread use and long-term application of azole antifungals in medicine? Drug Res Updat 11: 25-31.

140. Anderson JB (2005) Evolution of antifungal-drug resistance: mechanisms and pathogen fitness. Nat Rev Microbiol 3: 547-556.

141. Thaler GE, Slot JC (2015) Dimensions of Horizontal Gene Transfer in Eukaryotic Microbial Pathogens. PLoS Pathog 11: e1005156.

142. Richards TA, Leonhard G, Soanes DM, Talbot NJ (2011) Gene transfer into fungi. Fungal Biol Rev 25: 98-110.

143. Fitzpatrick DA, Logue ME, Butler G (2008) Evidence of recent interkingdom horizontal gene transfer between bacteria and Candida parapsilosis. BMC Evolut Biol 8: 181.

144. Fitzpatrick DA (2012) Horizontal gene transfer in fungi. FEMS microbiol let 329: 1-8.

145. Schönknecht G, Weber AP, Lercher MJ (2014) Horizontal gene acquisitions by eukaryotes as drivers of adaptive evolution. Bioessays 36 : 9-20.

146. Rolland T, Neuveglise C, Sacerdot C, Dujon B (2009) Insertion of horizontally transferred genes within conserved syntenis regions of yeast genomes. PloS ONE 4: e6515.

147. Coelho MA, Goncalves C, Sampaio JP, Gvoncalves P (2013) Extensive intra-kingdom horizontal gene transfer converging on a fungal fructose transporter gene. PLOS Genet 9: e1003587.

148. Mentel M, Spirek M, Ramberg JD, Piskur J (2006) Transfer of genetic material between pathogenic and food-borne yeasts. Appl Environ Microbiol 72: 5122-5125.

149. Hall C, Brachat S, Dietrich FS (2005) Contribution of horizontal gene transfer to the evolution of Sacchomyces cerevisiae. Eukar Cell 4: 1102-1115.

150. Kalkanci A, Kadioglu A, Wilson D, Jacobsen MD (2011) Gene expression in fungi. IMA Fungus 2: 29-32.

151. Houben M, Gabaldón T (2010) Acquisition of prokaryotic genes by fungal genomes. Trends Genet 26: 5-8.

152. EFSA Panel on Food Additives and Nutrient Sources added to Food (ANS) (2009) Scientific Opinion on the use of natamycin (E 235) as a food additive. EFSA J 7:1412.

153. JECFA. Specifications for the identity and purity of food additives and their toxicological evaluations: some antibiotics. In: Twelfth report of the joint FAO/WHO expert committee on food additives. July 1-8, 1968. Geneva, Switzerland; JECFA; 1968. WHO Technical Report Series No. 430/FAO Nutrition Meetings Report Series 45.

154. Anonymos. Basic overview of the regulatory procedures for authorization of veterinary medicines with emphasis on residues in food animal species.

155. European Medicines Agency. Maximum residue limits.

156. United States department of Agriculture. Food Safety and Inspection Service. National Residue Program for meat, poultry, and egg products. March 2015.

157. Department of Health and Human Services (US), Food and Drug Administration, Center for Veterinary Medicine. Guidance for industry \#152: evaluating the safety of antimicrobial new animal drugs with regard to their microbiological effects on bacteria of human health concern. 2003 Oct 23 